\title{
5 \\ PHILANTHROPY, CLASS, AND TAX IN FRANCE
}

\author{
Nicolas Duvoux
}

\section{Introduction}

Research on tax deduction for philanthropic purposes has developed in two main directions. First, following the concept of different countries belonging to non-profit regimes (Salamon and Anheier, 1998), the literature tends to highlight the 'crowding out' effect of high government expenditure on private philanthropic donations (Abrams and Shitz, 1978). Conversely, Arts and van Oorschot (2005) argue that high government expenditure coincides with a strong civil society. Second, the low price elasticity of donations (Fack and Landais, 2009) highlights that the majority of donations and higher gifts are concentrated at the top of the income distribution, eliciting sharp criticism about the plutocratic bias (Cagé, 2020). These developments resonate with critiques from the American context, on which the bulk of research on this subject is focused - most notably by Rob Reich (2018).

Economists focus on income and wealth as criteria for socio-economic inequality. However, occupational background matters for analysing income, wealth accumulation, and social status. Occupational backgrounds are important, as they define the hierarchy of autonomy at work and prestige, as argued by Goldthorpe (1996); these backgrounds also frame structured and stabilised perceptions of oneself and the world at large. Sociologist Michèle Lamont (2002) examines the different sets of values embraced by working-class members and managers in France and in the United States. The present chapter asserts that class is important with respect to perceptions of tax deduction for philanthropy. Thus, the diversity of relationships that donors at the top of the socio-economic ladder of France have with tax deductions is highlighted.

To do so, I draw on a qualitative set of ethnographic observations and semi-structured interviews with donors who created family foundations and enrolled them as big philanthropic players in France. These organisations have peculiarities which are detailed later in the chapter. These peculiarities allow an in-depth preliminary analysis of the diverse perceptions of tax deductions.

\section{The cultural sociology of the relationship between tax deductions and donations}

This section distinguishes this study from others on the impact of tax incentives for philanthropy in France. The latter are based more in economics and stem from the question regarding the 
relationship between public provision and private funding of the common good. Two concepts, namely the 'crowding in' and 'crowding out' effects, are defined in this field. France's position in cross-country comparison in terms of the share of GDP devoted to publicly financed social provision is high. It is among the countries with a low rate of donors, low percentage of philanthropic donations relative to the GDP, and, most significantly, low number of foundations related to the population (Salamon and Anheier, 1998). It is therefore quite logical that few researchers have studied the impact of tax deductions on philanthropy in this context. Fack and Landais's (2009) analysis shows that the efficacy of tax deductions is dubious. However, they also show that the higher the donor is in the income distribution, the greater is the impact of tax incentives on them. These two studies are dated and neither provide insights on the rapidly growing field of philanthropy nor illuminate the meaning-making processes through which donors perceive the role and the legitimacy of private funding for the common good as well as tax deductions for philanthropic giving (Box 5.1).

\section{Box 5.1 Tax deduction for philanthropic giving in France}

All organisations defined as "d'intérêt general" (general interest) are eligible for donations that can be deducted from the donor's taxes. There are three main incentives:

- For private individual donors: a tax deduction of $66 \%$ of the amount of the donation, up to a maximum of $20 \%$ of the taxable income;

- For companies: a corporate tax deduction of $60 \%$ of their donations, up to a maximum of $0.5 \%$ of their annual turnover (Source: French General Tax Code (CGI), articles 200 \& 238b;

- For individuals who own a real estate whose net worth is 1.3 million€t: a tax deduction of $75 \%$ the amount of the donation, up to 50,000€. The wealth tax is the result of reform that took place in 2018. Before 2018, the wealth tax concerned individuals who own a patrimony worth 1.3 million€+ be it composed of financial or real estate assets.

In this chapter, I will focus on this last tax deduction on a wealth tax that concerns the top 3\% of wealth concentration in France.

Broadening the scope and considering a wider set of tax deductions makes more data available. Sociologist and political scientist Alexis Spire (2018) presents one of the key insights provided by quantitative research. Using data representative of the adult population, he shows that those who pay more taxes also are, counterintuitively, those who accept higher taxation by the state. This paradox is resolved when tax deductions are considered because the wealthiest can take advantage of a wide range of tax deductions and exemptions for housing interest rests or repairs, for instance, home help services. This category consists of philanthropic donors. The most important thing is to consider, following Bourdieu's view (1979), that class does not only secure access to economic resources but also frames one's perceptions of themselves and of others; of one's identity and correlatively of their position in the outside world. The two are closely related in Bourdieu's relational sociology of positions in a field analysis. Empirically, Bourdieu's analysis of cultural capital can help create a better understanding of why philanthropy matters as a tool of distinction for the elite (Ostrower, 1995). 
Spire (2018) provides important insights on the social stratification of the relationship between philanthropy and tax deduction as a general category. However, the study does not analyse the variety of meaning-making processes associated with tax deduction for philanthropy. Therefore, I turn to a different analytical lens, using the tools of cultural sociology. Cultural sociology is a very dynamic field of research, notably in the American context, where the 'Culture' section of the American Sociological Association has evolved into one of the most important sections in quantitative terms. To provide a general overview of this field, it can be said, like Mohr et al. (2020:3) did, that:

Over the past few decades, cultural sociologists have amassed an impressive array of theoretical insights and modes of empirical investigation about how people create and interpret the meaning of the world around them. A central theme of this work is unpacking what meaning-making actually entails. Culture has turned from something that everybody in a given society has - whether that society is defined by national boundaries, language, or history - into a more stratified and segmented category. In this view, culture is not only the environment that enables the meaningfulness of social life but also a more specific set of scripts, narratives, embodied practices and schemas.

Among the various concepts put forward by this subject, I focus on 'frameworks'. This concept, inspired by sociologist E. Goffman's work (1974), can be defined as proposed by Lamont, Harding, and Small (2010):

How people act depends on how they cognitively perceive themselves, the world or their surroundings.

Cultural sociology aims at giving room to a variety of perceptions of one set of practices or institutions. More recently, cultural sociology has been blended with a neo-institutionalist agenda to broaden the understanding of inequality in the post-Piketty era (Lamont and Pierson, 2019). In our field of research, several studies show the relevance of this conceptual toolbox to create a better understanding of philanthropy. In her research on the anxieties of affluence, Sherman (2017) highlights the different meanings that wealthy families accord to philanthropy. Luna Glucksberg has studied the role of philanthropy in framing unequal gender relationships among the wealthiest families and how family offices have been used to secure a dynastic transmission of wealth (Glucksberg and Burrows, 2016). However, few studies have focused on the perception of tax deductions by families who benefit from them. From 2015 to 2017, I led in-depth ethnographic research, which provides elements to enrich our understanding of these processes. The bulk of this research draws on the seminal works of Lamont, which underline that class shapes perceptions and frameworks and self-understanding, as well as the perceptions of the world (2002). Precisely, the study of socioeconomics has become a more integrated field and has underlined the causal power of class on positions in the income distribution. This power remains strong and continues to grow over time (Albertini, Ballarino, and de Luca, 2020). We hypothesise that class is also important in shaping subjective views and is therefore important in shaping views on tax deductions. The distinction between small entrepreneurs and managers and professionals helps explain the diversity of meanings related to tax deduction for philanthropy among elite groups within the occupational structure. 


\section{Data}

My starting point is the idea that 'to study how individual giving responds to governments, information about the individual level of donations is required' (De Wit, Neumayr, Handy, and Wiepking, 2018:2) Few studies examine the formation of the cognitive mechanisms through which tax deductions for donations are perceived by individuals. To examine these mechanisms, I draw on a long-term ethnographic study led by one of the key French players in philanthropy. Through its grants, this foundation has funded a wide variety of non-profits and non-governmental organisations dedicated to fighting poverty and social exclusion in France and the world. Furthermore, it shelters small foundations created by wealthy families. It delegates its own entitlement to the maximum tax deduction available to them for individuals and households in France, 75\% (up to 50,000€ on wealth tax). Only foundations recognised by the French Council of State, which is in charge of authorising the incorporation of nonprofit organisations, can benefit from this deduction. Families who neither have the expertise nor the time to go through this very complex and time-consuming procedure are provided enrolment by big foundations which are already incorporated as 'RUPs' (reconnues d'utilite publique/recognised public-interest organisations). As a historian specialising in examining this procedure, Chloé Gaboriaux explains that the 'RUP' status has a centuries-long legacy in the French law system:

In France, 'Reconnaissance d'utilité publique' (RUP) has for a long time been the only way for foundations - endowment funds managed by a board of trustees - to exist and for associations - a group of people working together to achieve a common set of goals - to acquire a legal entity. It stems from a very ancient principle of medieval Roman law, which says that an organization cannot exist and act as a moral entity without being authorized by the State. In the 19th century, associations with more than 20 members could not be established without a prefectoral authorization (Article 291 of the Penal Code of 1810) and needed RUP to acquire legal capacity (or incorporation) - in order, that is, to hold property in their own name and to exist as a collective entity before the law.

(2019)

I draw on a long-term ethnographic study of a group of wealthy Parisian families who enrolled their foundations under the main foundation of interest. The relationship established with the foundation should be considered in order to understand how the material was collected. This foundation first asked me to lead the study with the explicit aim of interviewing some of the most important families among its clientele to anticipate the effects of a reform regarding the wealth tax on philanthropic donations. The foundation's manager wanted to know who, among its donors, would continue donating after a sharp decrease of charitable contribution deduction.

For two years, I was allowed to attend confidential meetings between donors and the staff regarding grant strategy, investments regarding the foundation's financial assets, expertise, and mentoring. I also attended most events organised for the donors' welfare, which included dinners, private concerts, work gatherings, and special events. These observations allowed me to obtain inside knowledge of the daily activities of the foundation and afforded me a certain level of familiarity with the families, which would be interviewed at the second step. In the late 2010s, the wealth tax was heavily criticised for imposing a burden on wealth, and it resulted in wealthy families leaving the country and creating businesses abroad. These arguments have been very important in conceptualising the wealth tax that was supported by Macron during 
the first year of his term, despite the fact that there is little evidence supporting them. Big foundations were nervous about the effects of such a possible outcome and were consequently willing to better know the families enrolled to be able to navigate these legal transformations. This prompted the foundation to open their doors to me. Therefore, in the semi-structured interviews, I focused on the donors' perceptions of the tax deduction. The questions were about the size and composition of wealth, structure of investments (housing, risky and nonrisky financial assets), philanthropic strategy developed, and relationship with the sheltering foundation. A sample of twenty families was constituted progressively, and I recorded interviews of more than two hours with each of them. I was able to follow five families more closely and had regular follow-up interviews and meetings with them at their homes. These families were selected because they presented very diverse objective as well as subjective features. The size of their wealth varied considerably, ranging from retired professionals who had accumulated wealth during their working years to industrial heirs or players in the financial sector. However, such a small dataset had obvious limitations and thus cannot be considered representative of wealthy French donors. The sample comprises organisations affiliated with a foundation having a peculiar position in the philanthropic sector. Being relatively open socially and liberal religiosity are the key features that distinguish the interviewed families from other philanthropists in France.

\section{Results}

This study draws on a qualitative subset of semi-structured interviews. Therefore, it does not aim at providing a representative picture of the way donors perceive the tax deduction they are benefited by. However, these data help create a better understanding of the arguments that structure the perceptions of philanthropy among the subgroups of donors that adopt different frameworks and of how their support of the common good is related to a wider perception of the role of the state.

\section{a $A$ critic of the wealth tax}

The first subgroup was strongly and explicitly opposed to the principle of a wealth tax. The legitimacy of this fiscal tool was heavily contested. At the time when the fieldwork was undertook, the wealth tax (Impôt de Solidarité sur la Fortune) was being criticised. This political context may have, therefore, favoured the expression of such a critique. The wealth tax was regarded as a predation by the state vis-à-vis entrepreneurs' legitimate gains:

People simply hate paying taxes. There is an extreme polarization on the wealth tax as you have to pay a share of your wealth yearly. For entrepreneurs like me who have worked to accumulate wealth, it is senseless to give it to a spendthrift state.

This kind of opinion is rarely expressed so bluntly. However, one should not underestimate the fact that it represents the collective view of a social group about the wealth tax. In her ethnographic research on the family offices that take care of the wealth of families, sociologist Camille Herlin-Giret notes the insistence on tax optimisation through various legal schemes (2019). Among these, some private bankers or family office employees recognise that the motivation for some philanthropic givers does not go far beyond the avoidance of the wealth tax. Taxpayers prefer to pay $25 \%$ more rather than pay the remaining percentage $(75 \%)$ to the state. Donating is, in this case, an ideological statement. It structures networks of friends and family members. 
As mentioned by a family foundation leader, the wealth tax avoidance helps structuring a network of donors. The leader details the annual contribution of one of his sons:

Among the six children of the family, one started his own business, which grew rapidly. It boomed over the years; he then sold the company. His cheque to the foundation represents his wealth tax. It is the most important resource of our foundation.

Another one clearly relates the occupational status of an entrepreneur with the avoidance of taxes:

Pay less tax. It is really the first motivation of entrepreneurs, therefore, it goes together.

A key feature of this framework is denying a sense of generality to the state. The state is personified to lower its legitimacy regarding tax raises on behalf of the people:

It is a bit senseless to give money to Mr Hollande or Mr Sarkozy. I prefer to make my choices.

Political leaders seem to view taxes as personal gains rather than contributions to the state's budget. State-sponsored taxation is considered an illegitimate predation by entrepreneurs who have spent their lifetime running businesses.

\section{b A search for efficacy}

Although various frameworks can be mixed in the discourse of a single interviewee, a second group of donors refers not so much to a refusal of the legitimacy given to tax but rather to a will to secure a greater efficiency of the money donated. As a matter of fact, donors often mention a consideration for impact. They want their money to be useful to the community and consider that private provision is a better means to achieve this goal. This is consistent with Bekkers and Wiepking's (2011) explanation of philanthropy driven by the quest for efficiency. Even though I do not focus on the motivations of donors per se and the way they perceive the tax deductions they are entitled to, my findings converge with those from a wide body of literature. Vis-à-vis tax deductions, the most important point is that donors do not value the absolute efficacy of their donation but rather the relative efficacy of their donation vis-à-vis the same amount of money dedicated to tax.

They think that the state has failed, and that poverty and inequality are growing. Paying taxes equals subsidizing a machine that is also broken. Donors are willing to pay a little bit more in order to have an impact on the ground thanks to the non-profits they have chosen and projects they know about.

Efficacy is therefore a strong element of the donor's perception of tax deductions for philanthropic purposes. They allow philanthropists to choose projects and to fund non-profits that emulate corporate values because they think that, however controversial this view might be, the latter are more prone to helping people to move out of poverty, for instance. While explaining to me the core principles driving his own foundation, a donor underlined the distinction 
between an environment that provides money and creates dependency and an environment which creates social mobility through training:

Our principle states that if a person is unwilling, even if the environment provides them with resources, they will not change their fate. Conversely, if a person is willing but the environment is not conducive, they will be impotent. . . My foundation is not dedicated to give a hand-out or to send cash to southern countries. We want people to thrive and lift the barriers that keep them from doing so.

Similarly, managers and professionals tend to think that tax deductions allow a greater efficacy for the money donated. They highlight the fact that the non-profits they fund replicate the impact measurement strategies (through the use of metrics) which they consider essential for running a corporation successfully. They are interested in the technicalities of implementation and often closely know the leaders of the non-profits. Tax deductions allow them to be involved in various projects and initiatives dedicated to eradicating poverty in France and abroad.

This last example shows how efficacy and values are intertwined. A last set of donors, often, if not always, the wealthiest of the families, tend to value the fact that through tax deductions, the state is providing a recognition of their own values, hence contributing to genuine pluralism.

\section{c Values and authenticity}

Tax deductions are a form of recognition of different sets of values by the state. This perception is common among families which are wealthy enough to continue giving without tax deductions. Moreover, one could argue that because they are high enough in income distribution, they are concerned not only for their positions but have also developed a concern for the welfare of the philanthropic sector itself. Therefore, their position vis-à-vis tax is both detached, because the social status and intrinsic gratifications attached to philanthropy do not depend on these tax deductions, and concerned, because they have a strong interest in influencing public choices. They can afford to give without being supported. However, they attach extreme importance to the fact that through tax deductions, the state is promoting a kind of pluralism, which is difficult to find in other fields of public intervention. This is consistent with the fact that for civil society organisations, non-profits, and foundations alike, government subsidies are seen as a 'seal of approval' (Schiff, 1990). During an interview, a foundation leader told me that:

The label is very important. Getting recognition for our contribution to the common good matters a lot. It makes the project credible for partners and sponsors. It is also a way to acknowledge that we are doing good work and that there is room for the kind of initiatives we have launched.

We are entitled and have supported promoting a certain vision of the world and of how its problems should be settled. We are not particulars, we are acting by our own convictions, on behalf of the state. In poverty relief, religious convictions are crucial.

The attachment to pluralism is very close to an argument put forward by Rob Reich. In his book, as in previous works, he asks if fiscal support for philanthropy and, ultimately, the contributions philanthropic foundations make to democracy can be justified and, if so, how. $\mathrm{He}$ believes they are. He considers two arguments often put across in this debate: that of pluralism and that of discovery. The argument on pluralism expresses that foundations contribute to a 
pluralistic conception of the common good and diversify the agents involved in defining it, making it possible to overcome a univocal and centralised conception of the public interest. However, while this argument is acceptable to a degree, it suffers a rather obvious plutocratic bias. The discovery argument argues that, contrary to the state and market, philanthropy can invest for the longer term and help discovering new paths, as in science, where interests are detached from immediate outcomes.

Even if it was possible to identify this plutocratic bias in the data I collected, I do not wish to make an argument for or against philanthropy. I simply wish to show that the attachment to pluralism is related to Catholic faith and a will to see Catholic welfare services as contributing to the common good. In a republic with a strong commitment to a neat distinction between religion and public affairs labelled and put forward under the banner of the defence of 'Laïcité, (secularism), tax deductions convey a discreet yet subjectively and objectively important contribution to a pluralistic implementation of various organisations. With the exception of the Foundation of France, the main players of the philanthropic sector are influenced by religion, be it a liberal or conservative Catholicism, Judaism, or Protestantism. This point is, therefore, a more general one: religious domination structures the philanthropic sector. This is also a point that is valid in the 'longue durée' (long duration) of history, as research has shown that the philanthropic networks of the 1900s Paris displayed, in a country heavily fragmented by an open crisis between the Republican State and the Catholic church, a peaceful coexistence of Republican and Catholic elites (Topalov, 2020).

\section{Discussion}

These results bring a descriptive and value-added view on the diversity of perceptions of tax deduction for philanthropic purposes displayed by a small set of donors enrolled in a liberal Catholic foundation. These results must be considered carefully, given the limitations of the qualitative sample, and must be contextualised against an era when the bulk of the wealth tax was still in place - which is no longer the case today. Nonetheless, they do provide insights on philanthropic initiatives and on the way donors perceive the tax deductions they benefit from. Understanding state support through fiscal deductions is not the same as understanding the motivations of donors, which are significantly more diverse. Obviously, studying the perceptions of tax deduction enhances the importance of the latter and may suggest that they are key for motivating donors as well as for unfairly obscuring the concern for the needs of those helped or the peer pressure to donate. However, as has been seen after the introduction of the wealth tax, tax deductions are crucial for forming positive perceptions of philanthropic donation.

A second value-added factor is to bring class back in the way we relate these perceptions with specific subgroups. Once again, I do not have the means to show a causal relationship between a given class and a given framework. Nonetheless, it is interesting to note that among the groups overrepresented at the top of the income and wealth distribution, two different frames of perception of tax deductions appear, and they are closely related to two different occupational backgrounds. On the one hand, the blunt dismissal of the legitimacy of the wealth tax comes from entrepreneurs, be they small or big. This is consistent with the longstanding political positioning of this group to defend oneself against taxation as well as mandatory social protection. On the other hand, professionals and managers who implement - or have implemented when retired - bureaucratic or economic rationality in their corporations display a strong attachment to efficacy and consider that the efficacy of donations privately is higher than when the state implements social services. As has been seen in the critique of cash transfers, consideration for 
values is not separated from consideration of efficacy. However, a specific subgroup, consisting of families with higher and more dynastic wealth, values tax deductions for their contribution to pluralism.

The latter finding has several important theoretical implications. For more than a decade, European sociology in general, and British sociology in particular, has debated the definition of class. Does the 'employment aggregate approach' (Crompton, 1993) capture a social stratification where wealth inequality plays a bigger role, as has compellingly been shown by Piketty (2014)? He argues that a social class map needs to take wealth into account for determining class (2020). This can lead to what Savage et al. (2013) called a new class map, inductively built and considering various dimensions of capital. This study aims to contribute to this agenda by taking another route, which is continuing to use occupations to examine class but doing it via cultural sociology, because it helps distinguish various meaning-making processes related to wealth through the study of the relationship the wealthy have to wealth tax. The aspects of economic capital as well as occupational status (former or current) appear to be salient in framing philanthropists' relationship to the wealth tax. These preliminary results call for a more integrated research agenda on the intertwining of class and wealth. It could provide additional knowledge in two main directions: on the one hand considering the impact of wealth all along the socio-economic ladder and, on the other, as this study shows, distinguishing the diverse social worlds that are composed by the top $1 \%$ of the income and wealth distribution. In this context, a predominantly qualitative, culturally sociological approach could contribute to highlight the varieties of meaning-making processes related to class at the top of the socio-economic ladder and conversely to make room for the multidimensional effects of wealth on class-based perceptions of oneself, other people, and the world at large.

\section{References}

Abrams, B.A.; M.D. Shitz, "The "crowding-out" effect of governmental transfers on private charitable contributions', Public Choice, 33(1), 1978, 29-39.

Albertini, M.; G. Ballarino; D. De Luca, 'Social class, work-related incomes and socio-economic polarization in Europe, 2005-2014', European Sociological Review, 36(4), 2020, 1-20.

Arts, W.A.; W.J.H. van Oorschot, 'The social capital of European welfare states: The crowding out hypothesis revisited', Journal of European Social Policy, 15(1), 2005, 5-26.

Bekkers, R.; P. Wiepking, 'A literature review of empirical studies of philanthropy: Eight mechanisms that drive charitable giving', Nonprofit and Voluntary Sector Quarterly, 40(5), 2011, 925-973.

Bourdieu, P., La distinction: Critique sociale du jugement, Paris: Editions de Minuit, 1979.

Cagé, J., The Price of Democracy: How Money Shapes Politics and What to Do About It, Cambridge, MA: Harvard University Press, 2020.

Crompton, R., Class and Stratification, Cambridge: Polity Press, 1993.

De Wit, A.; M. Neumayr; F. Handy; P. Wiepking, 'Do government expenditures shift private philanthropic donations to particular fields of welfare? Evidence from cross-country data', European Sociological Review, 34(1), 2018, 6-21.

Fack, G.; C. Landais, 'Les incitations fiscales au dons sont-elles efficaces?', Economie et Statistique, 427-428, 2009, 101-121.

Gaboriaux, C., 'A social construction of public interest: The "Reconnaissance d'Utilité Publique" of associations and foundations by the Council of State (1870-1914)', Histphil Blog, May 10, 2019.

Glucksberg, L.; R. Burrows, 'Family offices and the contemporary infrastructures of dynastic wealth', LSE Research Online Documents on Economics, 75899, 2016.

Goffman, E., Frame Analysis: An Essay of the Organization of Experience, New York: Harper, 1974.

Goldthorpe, J., 'Class analysis and the reorientation of class theory: The case of persisting differentials in educational attainment', The British Journal of Sociology, 47(3), 1996, 481-505.

Harding, D.J.; M. Lamont; M.L. Small, 'Reconsidering culture and poverty', The Annals of the American Academy of Political and Social Science, 629(1), 2010, 629. 


\section{Nicolas Duvoux}

Herlin-Giret, C., Rester Riche: Enquête sur les Gestionnaires de Fortune et Leurs Clients, Paris: Le bord de l'eau, 2019.

Lamont, M., The Dignity of Working Men: Morality and the Boundaries of Race, Class and Immigration, Cambridge, MA: Harvard University Press, 2002.

Lamont, M.; P. Pierson, 'Inequality as a multidimensional process', Special Issue of Daedalus: Journal of the American Academy of Arts and Science, 148(3), 2019, 5-19.

Mohr, J.W.; C.A. Bail; M. Frye; J.C. Lena; O. Lizardo; T.E. McDonnell; A. Mische; I. Tavory; F.F. Wherry, Measuring Culture, New York: Columbia University Press, 2020.

Ostrower, F., Why the Wealthy Give: The Culture of Elite Philanthropy, Princeton, NJ: Princeton University Press, 1995.

Piketty, T., Capital and Ideology, Cambridge, MA: Harvard University Press, 2020.

Piketty, T., Capital in the Twentieth Century, Cambridge, MA: Harvard University Press, 2014.

Reich, R., Just Giving: How Philanthropy Is Failing Democracy and How It Can Do Better, Princeton, NJ: Princeton University Press, 2018.

Salamon, L.; H.K. Anheier, 'Social origins of civil society: Explaining the nonprofit sector cross-nationally', Volontas: International Journal of Voluntary and Nonprofit Organizations, 9(2), 1998, 213-248.

Savage, M.; F. Devine; N. Cunningham; M. Taylor; L. Yaojun; J. Hjellbreke; B. Le Roux; S. Friedman; A. Miles, 'A new model of social class? Findings from the BBC's Great British class survey experiment', Sociology, 47(2), 2013, 219-250.

Schiff, J., Charitable Giving and Government Policy: An Economic Analysis, New York: Greenwood Press, 1990.

Sherman, R., Uneasy Streets: The Anxieties of Affluence, Princeton, NJ: Princeton University Press, 2017.

Spire, A., Résistances à l'impôt, attachement à l'Etat. Enquête sur les contribuables français, Paris: Le Seuil, 2018. Topalov, C., ed., Philanthropes en 1900. Londres, New York, Paris, Genève, Paris: Créaphis, 2020. 